\title{
A Rede de Urgência e Emergência da Macrorregião Norte de Minas Gerais: um estudo de caso
}

\section{The emergency network in the northern macro-region of Minas Gerais, Brazil: a case study}

\author{
Soraya Figueiredo de Sousa Torres \\ Secretaria de Estado de Saúde de Minas Gerais. Subsecretaria de \\ Gestão Regional. Belo Horizonte, MG, Brasil. \\ E-mail: sorayafsousa20ıзðgmail.com \\ Soraya Almeida Belisário \\ Universidade Federal de Minas Gerais. Faculdade de Medicina. \\ Departamento de Medicina Preventiva e Social. Belo Horizonte, \\ MG, Brasil. \\ E-mail: soraya®nescon.medicina.ufmg.br

\section{Elza Machado Melo} \\ Universidade Federal de Minas Gerais. Faculdade de Medicina. \\ Departamento de Medicina Preventiva e Social. Belo Horizonte, \\ MG, Brasil. \\ E-mail: elzameloळmedicina.ufmg.br
}

\section{Correspondência}

Soraya Figueiredo de Sousa Torres

Subsecretaria de Gestão Regional. Cidade Administrativa Presidente Tancredo Neves.

Rodovia Prefeito Américo Gianetti, $n^{\circ} 4.143$, Serra Verde, Prédio Minas, $12^{\circ}$ andar.

CEP 31.630-900. Belo Horizonte, MG, Brasil.

\section{Resumo}

A atenção a Urgência e Emergência é um desafio a ser enfrentado pelo Sistema Único de Saúde e demanda dos gestores a organização deste. Para atender a essa demanda, a Secretaria de Estado de Saúde de Minas Gerais propôs a construção da Rede de Atenção de Urgência e Emergência na Macrorregião Norte de Minas Gerais, sendo a compreensão de seu funcionamento o objetivo deste artigo. Trata-se de uma pesquisa qualitativa e exploratória do tipo estudo de caso. A coleta de dados foi feita mediante pesquisa documental, observação e entrevistas com informantes-chave, membros do Comitê Gestor e profissionais da Secretaria de Estado que acompanham a Rede de Atenção à Urgência e Emergência do Norte de Minas. Os resultados indicam dificuldades, facilidades e avanços no processo. Entre as facilidades, tem-se a implantação da rede, a criação do Comitê, a regionalização do Serviço de Atenção Móvel de Urgência, a adoção da classificação de risco e o suporte do Estado. Entre as dificuldades, estão o modelo de financiamento, a extensão territorial, o despreparo e a rotatividade dos profissionais. Já o avanço foi o maior acesso. Conclui-se ser este um processo complexo e dinâmico, que envolve diversos e diferentes atores. Trata-se de ação pioneira e ousada, que, a despeito das dificuldades, tem se mostrado bastante positiva.

Palavras-Chave: Gestão de Saúde; Emergência; Urgência; Rede de Atenção à Saúde; Integração de Sistemas. 


\section{Abstract}

The attention to the Urgency and Emergency sectors is a challenge to be faced by the Unified Health System and demands organization from the health managers. In order to respond to this demand, the State Secretary of Health has proposed the implementation of the Urgency and Emergency Attention Network in the Northern Macro-region of Minas Gerais, and this article, a qualitative and exploratory research in the form of a case study, aims to understand its function. The data was collected through documental research, observation and interviews with key-informants (members of the Managerial Committee and professionals of the Secretariat of State who accompany the Urgency and Emergency Attention Network in the North of Minas Gerais). The results point at difficulties, but also at positive aspects and advances. On the positive end are the network implementation, the Committee creation, the Emergency Mobile Health Care regionalization, the risk classification and the State support. On the negative end are the financing model, the large territory, the workers' lack of prepare, and their high turnover. As advances, the better access to the services is highlighted. The conclusion is that this is a complex and dynamic process that involves many different actors. This network is an innovative and audacious action, which, despite the difficulties, has proved to be very positive.

Keywords: Health Management; Emergency; Urgency; Health Care Network; Systems Integration.

\section{Introdução}

Entre os desafios a serem enfrentados pelo Sistema Único de Saúde (SUS), a atenção à Urgência e Emergência (UE) merece evidência, uma vez que sua ausência ou inadequação pode gerar incapacidade ou óbito do indivíduo (Brasil, 2002). Questões como mudanças demográficas e aumento de acidentes contribuem para a intensificação da utilização de serviços de saúde, em especial os de urgência, revelando a necessidade de sua estruturação pelos gestores de saúde (Henderson, 2013; Brasil, 2002).

$\mathrm{O}$ sistema regionalizado de emergência americano, implantado nos Estados Unidos na década de 1970, é assim considerado porque articula "sistema de saúde, hospitais e recursos humanos especializados, segundo um plano" sendo executado sob uma coordenação regional. Atualmente, esse sistema se expande para outras necessidades, como a atenção à criança com problemas graves de saúde e agravos, tais como doenças cardiovasculares. No geral, a regionalização do sistema de emergência é reafirmada por autoridades, gestores e profissionais como estratégia necessária porque, simultaneamente, permite o acesso ao melhor cuidado, segundo um amplo leque de gravidade, e garante o acesso ao cuidado especializado, que não poderia ser disponibilizado em centros locais (IOM, 2010).

No Brasil, a importância de um sistema de UE foi reconhecida pelo Ministério da Saúde na Portaria $\mathrm{n}^{0}$ 2048/2002, que estabeleceu os princípios e diretrizes dos Sistemas Estaduais de Urgência e Emergência, as normas e os critérios de funcionamento e a classificação e cadastramento de serviços (Brasil, 2002). Nessa perspectiva, é proposto, então, que cada estado organize seu sistema de UE, cuja estruturação é considerada essencial para a consecução dos princípios do SUS (Brasil, 2002). A efetivação da proposta pressupõe que o sistema de UE se organize sob a forma de rede e que esta incorpore serviços de diferentes complexidades (Santos et al., 2003).

É nesse contexto que a Secretaria de Estado de Saúde de Minas Gerais (SES/MG), com a finalidade de organizar a atenção da UE no Estado, propôs a construção da Rede de Atenção de Urgência e Emergência na Macrorregião Norte de Minas Gerais (RAUE/MNMG), implantada a partir de 2008. A escolha da macrorregião ocorreu em função das 
características da mesma: extensão territorial, dificuldade de acesso, fragmentação das ações, desigualdade na alocação de recursos e elevada taxa de mortalidade em anos potencias de vida perdidos por morte prematura (Marques, 2009). A macrorregião ${ }^{1}$ norte possui 86 municípios e nove microrregiões assistenciais de saúde (Minas Gerais, 2011a), ocupa uma área de aproximadamente de $122 \mathrm{mil} \mathrm{km²}$ e tem população de pouco mais de 1,5 milhão de habitantes (IBGE, 2012). Essa região é caracterizada por possuir baixa densidade demográfica de 12,6 hab./km²(IBGE, 2012), intensa desigualdade social e extensas áreas rurais, que impactam na gestão, organização da assistência, promoção e prevenção da saúde (Marques, 2009).

Já a gestão da RAUE/MNMG ficou a cargo da Comissão Intergestores Bipartite Macrorregional (CIB-M), em parceria com o Complexo Regulador (CR), constituído pela Central de Regulação Assistencial (CRA) e pela Central de Regulação do Serviço de Atendimento Móvel de Urgência (CRUE-SAMU) (Minas Gerais, 2011b). Em 2009, foi constituído o Comitê Gestor (CG) da UE como uma Câmara Técnica da CIB-M. O CG² é o espaço de discussão e implementação das ações do sistema da UE presidido pelo coordenador Estadual da Urgência e Emergência, sendo composto por aproximadamente 60 pessoas entre titulares e suplentes. Seus integrantes são gestores estaduais e municipais de saúde; coordenadores das Unidades Regionais de Saúde; prestadores de serviços; profissionais e técnicos de saúde; policiais militares, do corpo de bombeiros e representantes do controle social da macrorregião.

Esta pesquisa teve como finalidade compreender o funcionamento da RAUE/MNMG, a partir do estudo do seu Comitê Gestor.

\section{Método}

Trata-se de uma pesquisa qualitativa, exploratória, do tipo estudo de caso. A coleta de dados foi feita por pesquisa documental, observação e entrevistas semiestruturadas com informantes-chave. O projeto foi aprovado pelo Comitê de Ética em Pesquisa da Universidade Federal de Minas Gerais (Parecer $n^{0}$ ETIC oog8.0203.00o-11).

$\mathrm{Na}$ pesquisa documental, foram consultados documentos referentes à RAUE/MNMG e ao CG, tais como documentos de criação, atas, regimento, relatórios e deliberações. Os documentos foram disponibilizados pela SES/MG e pelo CG e foram analisados segundo as categorias deste estudo. Já a observação ocorreu mediante a utilização de roteiro específico. Foram observadas duas reuniões ordinárias do CG, realizadas em Montes Claros num intervalo aproximado de dois meses, com o objetivo de conhecer o funcionamento do CG. Os aspectos observados foram: planejamento, organização e dinâmica da reunião, participação dos membros e pautas.

Os informantes-chave foram escolhidos intencionalmente entre os integrantes do CG (6o integrantes) entre os membros que já estavam há pelo menos um ano no comitê. Também foram entrevistados um consultor da SES/MG e um secretário administrativo da regional, que acompanhavam o CG. As entrevistas foram realizadas em Montes Claros e em Belo Horizonte, no período de maio a outubro de 2011. As perguntas versaram sobre questões como funcionamento da rede, tomada de decisão do CG, dificultadores e facilitadores para funcionamento e efetivação da Rede, desafios, avanços e propostas de Rede.

Num total de 18 entrevistas, 16 foram analisadas, sendo 14 de membros do CG e duas de representantes da SES/MG dos níveis central e regional. Duas entrevistas não foram utilizadas, pois os entrevistados não atenderem aos critérios de seleção do estudo. As entrevistas foram individuais e gravadas mediante autorização dos participantes, que tiveram seu anonimato assegurado. Todas as entrevistas foram transcritas e o critério para o seu fechamento obedeceu à saturação de dados (Fontanella et al., 2008). A análise dos dados foi feita de acordo com a análise de conteúdo proposta por Bardin (2008). Após a leitura flutuante do material, foram definidas

\footnotetext{
1 Macrorregião de Saúde: "Base territorial de planejamento da atenção à saúde, que engloba regiões e microrregiões de saúde e oferta de alguns serviços da média complexidade de maior especialização e a maioria de serviços da alta complexidade”. (MALACHIAS; LELES; PINTO, 2010, p. 62).

2 COMITÊ GESTOR DA REDE DE URGÊNCIA E EMERGÊNCIA DO NORTE DE MINAS GERAIS. Regimento interno do Comitê Gestor da Rede de Atenção de Urgência e Emergência da Macrorregião Norte de Minas. Montes Claros, 2ooga.
} 
as seguintes categorias de análise: criação/implantação, funcionamento, dificuldades, facilidades, avanços e propostas.

\section{Resultados e discussão}

\section{Criação e Implantação}

A ideia de criar uma RAUE em MG remonta ao ano de 2006 e surge em consonância com a proposta de estruturação da rede assistencial do estado, integrante do Plano Mineiro de Desenvolvimento Integrado (PMDI), que traçou um planejamento estratégico para o Estado e definiu prioridades (Silva et al., 2009). Entre elas, está a proposta de Regionalização de Atenção à Saúde, que busca fortalecer a atenção no SUS, de forma regionalizada e cooperativa por meio da implantação de redes (Silva et al., 2009). Estas são entendidas como

Organizações poliárquicas de conjuntos de serviços de saúde, vinculados entre si por uma missão única, por objetivos comuns e por uma ação cooperativa e interdependente, que permitem ofertar uma atenção contínua e integral a determinada população, coordenada pela atenção primária à saúde - pres- tada no tempo certo, no lugar certo, com o custo certo, com a qualidade certa, de forma humanizada e com equidade - e com responsabilidades sanitária e econômica e gerando valor para a população (Mendes, 2011, p. 82).

Sua concepção tomou algumas experiências internacionais como fonte de inspiração.

[...] quando nós começamos a discutir, já estava embrionária esta ideia da conversa com a Atenção Primária que era o sistema utilizado na Inglaterra, do Manchester [...] a discussão de rede da Itália [...] depois fomos a Portugal também, [...] (E1).

O diagrama a seguir (Figura 1) ilustra o processo de elaboração do desenho da rede para o estado. Cinco elementos foram definidores para a sua consecução: financiamento (investimento estadual); definição do modelo de governança (CIB e Complexo Regulador); delimitação da população/território (macrorregião); logística (SAMU macrorregional); e o modelo de classificação de risco (linguagem integrada entre os pontos de atenção em urgência com a adoção do Protocolo de Manchester).

Figura I - Processo de elaboração do desenho da Rede de Atenção à Urgência e Emergência

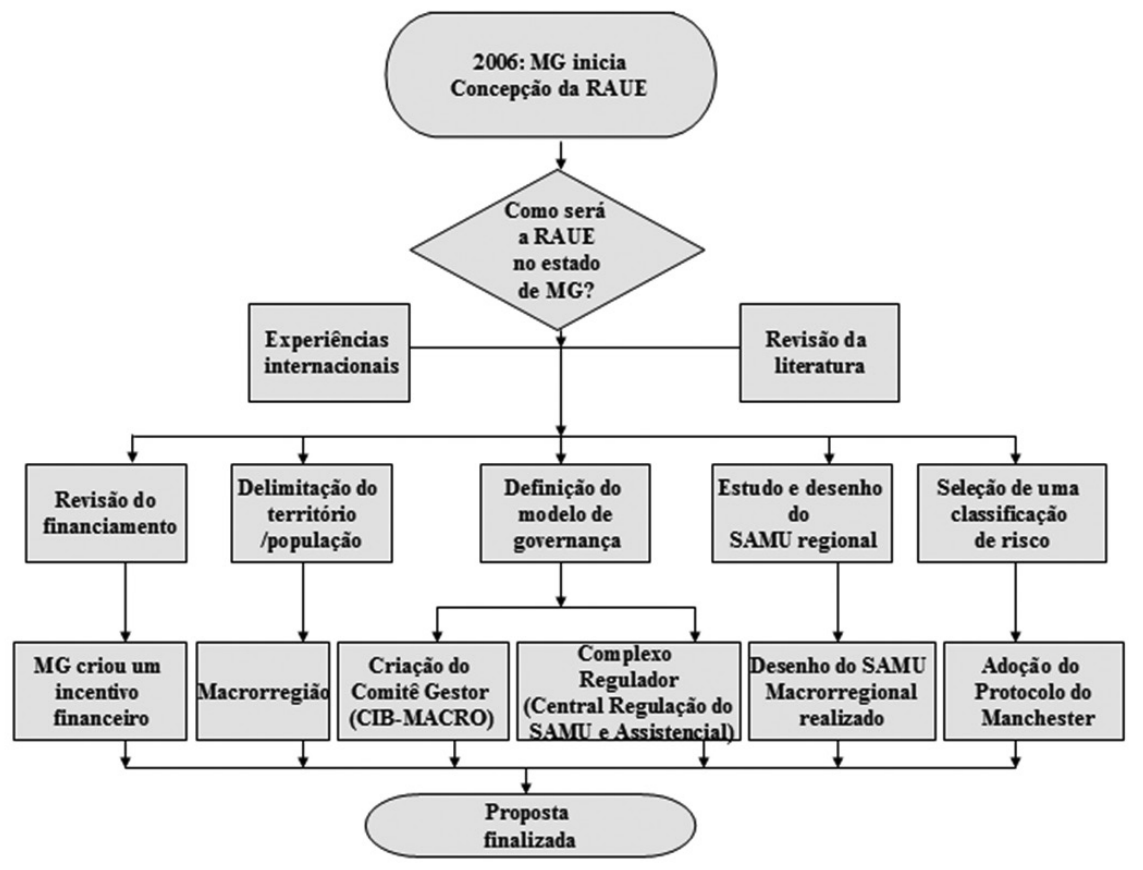


Após esse planejamento inicial, foi apresentada a proposta ao gestor estadual, que a considerou demasiado complexa e de difícil execução. Reapresentada em 2007, foi então realizado um projeto piloto. A escolha do território ocorreu após alguns estudos sobre as regiões do estado, no sentido de identificar a mais apropriada.

A região escolhida na época foi a região Norte por uma série de fatores: [...] facilidade do ponto de vista de integração entre os municípios [...] pela carência crônica deles; eles tinham já uma história de consorciamento bem desenvolvido; existia um polo [...] de grande porte que a cidade de Montes Claros; já existia um SAMU em Montes Claros bem avaliado, [...]; e já existia [...] um estudo dos Anos Potenciais de Vida Perdido, e que aquela região impactava a implantação da Rede (E1).

O processo de sensibilização e divulgação da RAUE/MNMG ocorreu por meio da realização de oficinas, das quais participaram gestores, profissionais de saúde, prestadores de serviço, entre outros, ficando cada microrregião responsável pela multiplicação da metodologia em seu território.

A implantação da Rede começou primeiramente com as oficinas de sensibilização, [...] Porque ela ia mudar um paradigma daquele atendimento fragmentado e cada município era responsável pelo seu atendimento em relação à urgência e emergência (Ез).

As oficinas resultaram na realização de diagnóstico situacional com a definição e tipologia de 18 pontos de atenção hospitalares; na localização das 37 bases do SAMU com definição e distribuição de 47 ambulâncias integrantes do sistema macrorregional (Marques et al., 2010).

A RAUE/MNMG foi inaugurada em dezembro de $2008^{3}$, simultaneamente à operacionalização do SAMU na região. A constituição do CG ocorreu em 19 de fevereiro de $2009^{4}$. Concomitantemente, a SES/MG publicou a Resolução ${ }^{0}{ }^{1.771 / 2009}$ (Minas Gerais, 2009), que aprovou as normas gerais para implantação do incentivo aos hospitais da RAUE/ MNMG. Para o entendimento da função do Comitê, foi realizado um curso de capacitação para os participantes da oficina, coordenado por consultores da Secretaria.

Segundo o Ministério da Saúde, o CG representa:

O espaço formal de discussão e implementação das correções necessárias à permanente adequação do sistema de atenção integral às urgências, dentro das diretrizes estabelecidas pelos Planos de Atenção às Urgências, em suas instâncias de representação institucional que permitirão que os atores envolvidos na estruturação da atenção às urgências possam discutir, avaliar e pactuar as diretrizes e ações prioritárias, subordinadas às estruturas de pactuação do SUS nos seus vários níveis (Brasil, 2011, p. 9).

A implantação da RAUE/MNMG ocorreu de acordo com o entendimento de Inojosa (1999), que afirma que a rede representa parceria que pode abarcar e fomentar relações interpessoais, interorganizacionais, intergovernamentais e intersetoriais. Para Santos et al. (2003), é importante que as ações de saúde sejam realizadas em redes, obedecendo e fortalecendo os princípios organizacionais do SUS. Na UE, esses autores acrescentam que a rede de atenção deverá ser constituída agregando serviços de todas as complexidades, o que foi constatado na estruturação da RAUE/MNMG. Da criação da RAUE desdobrou-se a publicação da Resolução $n^{\circ}$ 2.607, da SES/MG, de 07 de dezembro de 2010, que aprova as normas gerais para a implantação das Redes Regionais de Urgência e Emergência no estado de Minas Gerais (Minas Gerais, 2010). Posteriormente, em julho de 2011, foi publicada a Portaria $n^{0} 1.600$ que reformula a Política Nacional de Atenção às Urgências e institui a Rede de Atenção às Urgências no SUS.

3 COMISSÃO INTERGESTORES BIPARTITE MACRORREGIONAL NORTE DE MINAS GERAIS. Relatório da $25^{\circ}$ reunião ordinária. Montes Claros, 2008.

4 COMITÊ GESTOR DA REDE DE URGÊNCIA E EMERGÊNCIA DO NORTE DE MINAS GERAIS. Ata da reunião realizada em 19 de fevereiro de 2009: constituição do Comitê Gestor da Rede de Atenção de Urgência e Emergência da Macrorregião Norte de Minas. Montes Claros, 2oogb. 


\section{Funcionamento}

Segundo um entrevistado, a RAUE/MNMG está bem-estruturada em seus elementos constituintes - logística e pontos de atenção definidos; CG como instância mediadora; e CIB como instância deliberativa:

[...] eu acho que ela está estruturada: tem linguagem; tem logística; tem os pontos definidos; tem o Comitê para mediar tudo isso; tem a CIB, que é a instância deliberativa [...] (E15).

Para seu funcionamento, criou-se o Complexo Regulador (CR), composto pela Central de Regulação Assistencial (CRA / central de leitos) e pela Central de Regulação do Serviço de Atendimento Móvel de Urgência (CRUE-SAMU). Todas as decisões são tomadas pelo CR. Estruturação semelhante foi adotada pelo município de Guarulhos (SP), que iniciou seu processo de implantação de um Complexo Regulador Municipal em 2006, constituído pela central de regulação hospitalar, central de regulação ambulatorial e central de urgências (Mendes; Silva, 2010).

A CRA estabelece uma interlocução com o gestor estadual, com os gestores municipais, com os usuários, com as direções hospitalares e com os promotores públicos. Essa central está interligada com as nove microrregiões pelo sistema on-line SUS-FÁCIL e funciona em caráter de plantão, 24 horas. A competência da CRA é a de regular o leito da urgência e do procedimento eletivo.

A CRUE-SAMU é a responsável pelo primeiro atendimento ao paciente e pela sua transferência à RAUE/MNMG. O SAMU é regionalizado, com sede nos municípios de referência, seu financiamento é tripartite, e sua operacionalização acontece por meio de consórcio público firmado entre os municípios da macrorregião. O SAMU visualiza toda a rede e interliga cada ponto dela. Trabalha, também, com protocolos de referência e possui um Núcleo de Educação Permanente (NEP), que tem qualificado as portas de entrada do sistema. Estratégia semelhante de SAMU regionalizado foi utilizada em Santa Catarina (2003).

Segundo Machado, Salvador e O’Dwyer (2011), o SAMU é composto por uma central reguladora e um conjunto de ambulâncias, que demandam pro- fissionais qualificados e equipamentos necessários para a atenção à urgência. Os autores acrescentam que, apesar da inspiração internacional, no Brasil, o SAMU adquiriu características próprias, o que pode ser constatado neste estudo.

O CG é uma Câmara Técnica da CIB e sua função é registrar, ajudar e solucionar questões relacionadas ao funcionamento da RAUE: $O$ Comitê não é de decisão, mas os referendos do Comitê, quase sempre, ou sempre são acatados pelo estado, como uma política (E16).

Os comitês gestores são destacados por O’Dwyer (2010), que os define como importantes no planejamento do atendimento, especialmente na integração dos serviços, realizada a partir de interesses de vários e diferentes municípios.

No processo de tomada de decisão do CG da RAUE/MNMG, as situações conflitantes e/ou complexas são abordadas com a criação de comissões internas ou câmaras técnicas, as quais propõem soluções aos problemas identificados. As pautas são solicitadas pelos membros e definidas conforme as prioridades dos participantes. Sua distribuição é feita no início de cada sessão, sendo, entretanto, permitida a inclusão de novos temas.

Referindo-se, ainda, ao funcionamento, é preciso considerar os pontos de atenção que integram a RAUE/MNMG: atenção primária e hospitais micro e macrorregionais.

Para Mendes (2011), a importância da implantação das redes para a organização da atenção à saúde encontra-se na busca de superação da fragmentação dos sistemas de saúde, permitindo a gestão dos diversos pontos de assistência à população. Assim, a APS, definida como a porta de entrada do sistema, tem reconhecida tanto a sua importância estratégica como a necessidade de seu bom funcionamento para o desempenho da RAUE/MNMG.

A atenção primária é a base para todas as redes. [...] Urgência e emergência você ainda pode ter entrada direta nos hospitais dependendo da sua situação, mas uma parcela ainda vai passar pela atenção primária (E15).

Foi definida, também, a implantação da classificação de risco nas Unidades Básicas de Saúde (UBS), 
por meio do Protocolo de Manchester (Marques, 2009). Segundo Cordeiro Júnior (2008), experiências internacionais indicam que a classificação de risco é a base da RAUE, sendo, portanto, estruturada em diretrizes clínicas. Tal fato foi considerado na criação da RAUE/MNMG e está sendo incorporado como rotina nos pontos de atenção. Recentemente, passaram a ser dados incentivos financeiros para a efetivação da classificação de risco no Estado de Minas Gerais, conforme Resolução SES n ${ }^{0} 2.838$, de 14 de junho de 2011 (Minas Gerais, 2011c).

\section{Dificuldades}

O financiamento está entre as dificuldades elencadas pelos entrevistados, que apontam mais especificamente a insuficiência dos recursos, bem como a inadequação do tipo de repasse dos mesmos - pagamento por procedimento, estabelecido pela Programação Pactuada Integrada (PPI). Destacou-se também o baixo investimento federal na área, a ausência de reajustes periódicos, o baixo valor pago aos procedimentos realizados e a insuficiência de recursos para o pagamento dos profissionais também foram destacados: [...] todos nós sabemos que no SUS, há quase 10 anos, não se reajusta procedimentos. E quando os reajustes ocorrem pontuais $e$ se você analisar no seu faturamento é menos de $1 \%$ em 10 anos (E15).

Por razões diferentes, o financiamento também é uma dificuldade no sistema norte-americano (IOM, 2010), justificada pela tensão entre o mercado, que governa as relações na sociedade norte-americana, e a cooperação, que caracteriza a regionalização. Para os norte-americanos, regionalizar significa esvaziar, empobrecer ou sobrecarregar o nível local (IOM, 2010). Acredita-se que no Brasil, a existência do SUS com financiamento público e institucionalizado facilitaria a abordagem desse tipo de resistência.

O financiamento do SUS é discutido por diversos autores (Mendes; Marques, 2009; Dain, 2007). Para Dain (2007),

Do ponto de vista da necessidade incontornável da população por mais e melhores ações e serviços públicos de saúde, é essencial que o SUS possa alcançar novo patamar de gastos, compatível com a superação dos vazios sanitários e com as desigual- dades regionais e setoriais que ainda caracterizam o acesso e a utilização de serviços produzidos pelo sistema (p. 1852).

O subfinanciamento limita a atuação dos gestores no cumprimento dos compromissos pactuados, dificulta o pagamento, a manutenção e o investimento em qualificação de profissionais de saúde, provocando descontinuidade do atendimento. 0 não cumprimento pelos municípios das ações pactuadas reflete também no SAMU, aumentando viagens e custos operacionais.

O pagamento por procedimentos é considerado inadequado para o serviço de urgência. Tal fato entra em contradição com a própria concepção do que deve ser uma RAUE.

[...] Ele é um modelo ruim. [...] porque o hospital $X$, se ele fizer, ele vai receber, se ele não fizer, ele não recebe. [...] eu não posso pagar a urgência da mesma forma que eu pago um procedimento eletivo [...] A urgência tem uma lógica parecida com a Defesa Social, ou seja, eu pago para você ficar ali esperando (E1).

Em relação aos recursos humanos, as dificuldades apontadas são: qualificação e preparação inadequadas para atuação na urgência, insuficiência de profissionais e especialistas, dificuldade de fixação dos profissionais, rotatividade e baixa remuneração.

Não tem uma política, a atenção primária não tem uma política de fixação do profissional. Não tem uma política de formação, não tem uma política de valorização do profissional. O salário quem dita é o mercado, não existe uma política pública de salários (E15).

A sub-remuneração e a precariedade das relações trabalhistas diminuem a adesão dos profissionais ao SUS (Goulart, 2011). Constata-se que não há muito interesse dos profissionais pela UE, sendo poucos aqueles que a percebem como um local para o desenvolvimento de uma carreira e/ou de pesquisa. Geralmente os setores de emergência dos hospitais representam a primeira oportunidade de emprego de jovens médicos e enfermeiros, que permanecem 
nesses cargos até estabilizarem sua situação profissional e financeira (Scarpelini, 2007).

No que tange à rede assistencial, as dificuldades apontadas foram: desequilíbrio entre as microrregiões, que apresentam graus diferenciados de organização dos serviços de saúde; predomínio de hospitais de médio e pequeno porte e seu despreparo para o atendimento aos doentes mais graves; não cumprimento dos procedimentos pactuados pelas microrregiões, sobrecarregando a macrorregião no atendimento hospitalar. Nesta última constatou-se que a macrorregião tem atendido tanto à média como à alta complexidade: Um desses problemas são: as microrregiões ${ }^{5}$ não estão fazendo o papel delas, com isso, superlotando a noss a macro e dificultando os hospitais maiores de receber os pacientes da urgência e emergência (E1o).

O fato de os hospitais serem, em sua maioria, filantrópicos ou privados também acarreta dificuldades, uma vez que não há disponibilidade suficiente de leitos para o SUS. Aliada a isso está a desigualdade na distribuição dos hospitais nas microrregiões em relação à tipologia e ao número de unidades:

[...] algumas micros(regiões) com 4 ou 5 hospitais inseridos na Rede de Urgência e Emergência e outras micros(regiões) com apenas um hospital. Alguns hospitais com a micro(região) muito grande e com apenas dois hospitais. [...] Eu acho que éuma distribuição meio que equivocada [...] (E14).

Entre as dificuldades do SAMU destacam-se a manutenção dos profissionais e sua vinculação federal, o que dificulta e encarece a manutenção e a reposição dos equipamentos e implantação de transporte aeromédico próprio.

Sobre a CRA, os entrevistados ressaltam que há dificuldades no exercício de sua função, pois há resistência dos prestadores e dos profissionais em atendê-la, ou seja, em reconhecer seu poder sanitário: Na prática, a Central autoriza para um determinado hospital, mas esse determinado hospital não aceita, e, aí, a Central não pode fazer nada apesar dela ter poder sanitário para isso. Ela deveria ter como intervir [...] (E9).

A ação do poder judiciário também é referida como dificuldade para a CRA, na medida em que a ordem judicial é soberana em relação à regulação, definindo sobre a disponibilização de leitos e sobre a permanência de profissionais.

o paciente ter que ficar no CTI, mas eu quero que o médico do SAMU fique com ele até achar UTI [...]. Aí, o SAMU vai para lá e fica dentro da UTI, que tem um plantonista. $\varepsilon$ o médico do SAMU não arreda o pé. Só tem ele de plantão dentro da ambulância. Pode cair um paciente da urgência ali que ele não pode arredar o pé da UTI, senão ele paga dois mil reais por dia que é a multa que o juiz expede (E1o).

A extensão territorial, a densidade populacional, as barreiras geográficas, as estradas e os longos deslocamentos também foram dificuldades relatadas: Nós temos locais de difícil acesso. O Rio São Francisco praticamente passa cortando a nossa macro(região) ao meio. Nós temos cidades do outro lado do São Francisco que para chegar até essas cidades são (utilizadas) balsas (E3).

Alguns autores relatam que a geografia, a demografia, a condição socioeconômica os aspectos culturais e profissionais, as condições de investimento em saúde, da região, entre outros, são fatores que interferem na acessibilidade aos serviços de saúde (Lopes, 1989; Garlet et al., 2009).

A frágil organização da APS na região é colocada como uma dificuldade pelos entrevistados, por possibilitar que a UE funcione como a porta de entrada do sistema: [...] observa-se uma fragilidade na APS em alguns municípios, uma vez que os mesmos não têm uma boa cobertura de PSF, o que faz com que os pacientes se dirijam diretamente à rede hospitalar para serem atendidos (E11).

Achado semelhante a esse está presente no trabalho (O’Dwyer et al., 2008) que identificou várias referências negativas à Atenção Básica do Estado do Rio. Para os autores, "com a melhor definição da rede

\footnotetext{
5 Microrregião de Saúde: "Base territorial de planejamento da atenção secundária com capacidade de oferta de serviços ambulatoriais e hospitalares de média complexidade e alguns serviços de alta complexidade, constituída por um ou mais módulos assistenciais. Apresenta nível tecnológico de média complexidade e abrangência intermunicipal”. (MALACHIAS; LELES; PINTO, 2010, p. 62).
} 
e fortalecimento do PSF, pode ser que os serviços de emergência deixem de ser a real e principal porta de entrada do sistema e que o processo de trabalho nesses serviços seja mais compatível com a sua missão" (p. 1645).

O fato de o CG não ser instância deliberativa também é apontado como problema, pois a CIB-M muitas vezes incorre nessa questão e, consequentemente, não homologa as decisões do CG: Mas uma questão que tem entrave é a questão do CIB. Porque não adianta o Comitê ser extremamente técnico e tal. Mas se a CIB não homologar, não adianta, pois a instância que homologa é a CIB (E15).

Por fim, dificuldades semelhantes ao do sistema brasileiro foram verificadas no sistema norte-americano, tais como qualificação, quantidade e distribuição dos recursos humanos (IOM, 2010; Henderson, 2013), heterogeneidade das regiões, dificuldade de regulação e coordenação, assim como algumas potencialidades (IOM, 2010).

\section{Facilidades}

As facilidades apontadas correspondem às melhorias no acesso e na estrutura dos serviços, sendo o compromisso dos atores no processo de implantação e consolidação da RAUE/MNMG.

Em relação ao acesso, destaca-se o asfaltamento das estradas da região e a implantação da telefonia celular. Destaca-se, também, a criação e consolidação do SAMU, considerado primordial à efetivação da RAUE/MNMG, com seu sistema logístico de transporte e equipe forte e competente: Outro fator facilitador é, com certeza, ofuncionamento do nosso $S A M U$ regional, que a gente sabe que é muito difícil o norte de Minas, a carência que temos de profissional, de hospital (E6).

A existência de um CR com comando único, organizado e articulado também foi ressaltada: Complexo Regulador, a rede tem que ter um comando único. [...] você vai levar o paciente no lugar certo, no ponto certo, na hora certa, no momento que é importante, no ponto de atenção certo (E17).

Outras facilidades logísticas são o suporte técnico fornecido pela empresa de processamento de dados do estado, o serviço de internet, a utilização do Telessaúde e a adoção do Protocolo de Manchester nos pontos de atenção.
Sobre o CG, foram relatados como facilidades o envolvimento de seus integrantes, a periodicidade das reuniões e a presença constante do Coordenador Estadual: O fator facilitador [...] é o nosso Comitê. [...] todos os participantes da Rede, hospitais e município, estão totalmente envolvidos com relação a esse Comitê (E6).

A adesão dos municípios à proposta com o consequente entendimento de seu papel e sua aceitação do trabalho compartilhado na Rede também foram apontadas como facilidades: [...] o que tem facilitado, primeiro, é a adesão dos municípios. Todos os municípios entenderam seu papel, aderiram, e a discussão vem sendo feita mensalmente (E12).

A atuação da SES/MG é outra facilidade levantada, com os seguintes destaques: a continuidade do então secretário de saúde; as respostas às demandas apresentadas; as orientações nas áreas jurídica e administrativa e o trabalho e suporte propiciados por elas; a construção democrática e transparente do processo e seu papel indutor no processo de regionalização. [...] é o mesmo secretário, então ele está dando continuidade ao projeto. Não é aquele negócio, muda o político e muda todo mundo e o projeto é esquecido $\left(\mathrm{E}_{7}\right)$.

Há o entendimento de que a Rede facilita a organização do gestor municipal possibilitando um maior planejamento das ações.

[...] a oportunidade que os gestores estão tendo de poder aprofundar na atenção primária. Porque uma vez que você tem ali uma gestão da urgência e emergência, o gestor tem mais tempo para planejar, organizar a atenção primária e promover a saúde nos seus municípios (E11).

Por fim, a decisão política de criação da Rede e o apoio recebido pelos políticos locais também foram destacados pelos entrevistados: $\varepsilon u$ acho que um facilitador é isso, os políticos aqui da região são líderes, eles querem o bem do norte (E7).

\section{Avanços}

Referente ao aumento do acesso e à melhoria da assistência, a implantação da RAUE/MNMG é considerada um avanço para os entrevistados. Tais fatores 
contribuíram para o aumento da resolutividade dos eventos e para a integração dos pontos de atenção. A estruturação do SAMU regional é considerada como um fator importante para o aumento do acesso e para a capacidade resolutiva da RAUE/MNMG:

Este éum processo que acontece até porque o SAMU pressiona. Se eu tenho uma rede pactuada, ele passa a levar alguns pacientes que não chegavam. [...] Eles passam a chegar e a rede tem que ficar realmente resolutiva $\left(\mathrm{E}_{1}\right)$.

Outros avanços apontados referem-se à melhoria na capacidade de resolução dos serviços e à descentralização de serviços de média e alta complexidade para outros municípios da macrorregião:

[...] antes só tinha CTI em Montes Claros e hoje tem CTI em vários lugares. [...] $O$ atendimento médico de alta complexidade praticamente era só aqui. Hoje já tem em Pirapora, Janaúba, Taiobeiras, Salinas, Januária, Brasília de Minas (E16).

Por fim, a criação do CG também foi considerada um avanço nesse processo:

Então, foi um avanço muito grande porque nós temos resultados muito bons [...] Hoje nós temos essa instância de negociação, [...] um diálogo mais técnico [...] a questão da saúde era muito envolvida com as questões políticas. Hoje, está mais se preocupando com a questão técnica, [...] com o bem-estar dos pacientes (E11).

Apesar dos avanços apontados, os entrevistados concordam que o funcionamento da Rede ainda não atingiu o patamar desejado, o que demonstra a necessidade de continuidade, de melhoria e do aumento dos recursos destinados a ela.

Isso ainda não funciona da forma como a gente quer, mas podemos constatar avanços impressionantes e já um entendimento maior sobre o funcionamento da Rede (E11).
[...] É uma ideia fantástica. Tem muita coisa a melhorar? Tem. Os recursos são poucos? São. Precisa ser modificado isso? Com certeza. Tem muita gente fazendo sacrifício (E16).

\section{Propostas}

As propostas apresentadas estão relacionadas: ao financiamento; ao redesenho da RAUE/MNMG; às atribuições do CG; às relações entre os poderes constituídos; e à divulgação da experiência. Sobre o primeiro, é proposta a mudança do modelo por procedimento, e, para isso, os entrevistados sugerem o entendimento entre as instituições envolvidas (MS, SES e COSEMS).

Propõe-se que o redesenho da RAUE/MNMG seja baseado em critérios demográficos e geográficos, no intuito de conferir maior equidade à distribuição dos serviços: Acho que seria interessante [...] elaborar um estudo para verificar essa equidade de distribuição desses hospitais [...] em todas as micros [regiões]. É uma reestruturação desse desenho inicial. (E14).

Sugere-se também o estabelecimento de metas para os recursos repassados aos prestadores, para que sejam utilizados para os devidos fins, sendo um deles o monitoramento realizado pela SES/MG.

Seria interessante ocorrer o monitoramento por parte da SES para estabelecer alguns critérios para os hospitais utilizarem esse recurso. Monitoramento com relação à meta, porque o estado repassa o recurso para o hospital e, pelo o que eu percebo, mais de 95\% dos hospitais, realizam, utilizam esse recurso com pagamento de profissionais (E6).

Sobre o CG, a proposta é que o mesmo se converta numa instância deliberativa, o que agilizaria a tomada de decisão. A boa experiência do CG fez com que fosse sugerida a criação de estrutura semelhante nos demais projetos da SES/MG: [...] existe uma proposta até do COSEMS macro(região) norte que se crie Comitê Gestor para outras áreas da Secretaria de Estado da Saúde, como Viva Vida ${ }^{6}$ (E12).

6 Viva a Vida: (Programa de Redução da Mortalidade Materna e Infantil de Minas Gerais de 2003 a 2014). 
Por fim, sugere-se, também, a realização e publicação de estudos, a utilização da mídia, entre outras estratégias para a ampliação da RAUE.

[...] falta o cidadão Sr. João que está lá na ponta entender (um) pouco melhor isso. [...] Eu acho que isso devia ir para a mídia, numa linguagem que a população entendesse qual é a função do SAMU, por que o SAMU existe (E15).

\section{Considerações finais}

Neste estudo, observou-se que a implantação de uma RAUE, é complexa, dinâmica e envolve diversos e diferentes atores. Em Minas Gerais, esse processo não foi diferente. Embasada em evidências e experiências internacionais, a RAUE/MNMG é fruto de uma decisão pioneira e ousada e, apesar das dificuldades apontadas, tem se mostrado positiva. Entre os avanços alcançados está a criação do CG, fórum de gestão que favorece a busca de soluções para as dificuldades encontradas. Os depoimentos colhidos e a observação de seu funcionamento demonstram sua importância e legitimidade.

As Redes de Atenção à Saúde (RAS) são constituídas por três elementos: a população, a estrutura operacional e o modelo de atenção (Mendes, 2011), todos eles identificados na RAUE/MNMG. Acredita-se que uma reavaliação da distribuição da tipologia hospitalar e das bases do SAMU poderá aprimorar o seu funcionamento, conforme mencionado por alguns entrevistados. Já a APS foi apontada como necessária à melhoria do seu desempenho.

Observou-se, também, a relevância do CR na gestão do sistema, em especial a atuação do SAMU, que se articula diariamente com os componentes da RAUE/MNMG, superando o entendimento de ser apenas um apoio logístico. Já a CRA busca constantemente o gerenciamento dos leitos, encontrando algumas dificuldades no desempenho de sua função.

Outro fator relevante é a participação do estado, facilitando a compreensão dos desafios e a busca de soluções para os problemas. Os investimentos em projetos estruturadores para a saúde e outras áreas também são detectados como pontos positivos. É necessária, ainda, uma maior aproximação entre os entes federados, Universidades e Conselhos de Classe, para discutir e propor soluções aos problemas identificados (como a baixa remuneração, a rotatividade e as deficiências na formação dos profissionais).

O financiamento apresentou-se como um ponto crucial ao bom desempenho da RAUE/MNMG, o que demonstra a necessidade de sua revisão e incremento, cabendo aos gestores do SUS essa discussão.

Destaca-se, por fim, o comprometimento e a determinação de todos os envolvidos na melhoria e consolidação da proposta independentemente dos desafios a serem enfrentados, numa demonstração da irreversibilidade do processo.

A proposta da RAUE/MNMG, como uma experiência pioneira no Brasil, impõe limitações a este estudo ao mesmo tempo em que aponta para a necessidade de outros. Espera-se que esta pesquisa contribua não só para um melhor entendimento da RAUE/MNMG como também para a implantação de outras redes semelhantes no Brasil.

\section{Referências}

BARDIN, L. Análise de conteúdo. 4. ed. Lisboa: Ed. 70, 2008.

BRASIL. Ministério da Saúde. Portaria nº 2.048, de 5 de novembro de 2002. Aprova, na forma do Anexo desta Portaria, o Regulamento Técnico dos Sistemas Estaduais de Urgência e Emergência. Diário Oficial da União, Brasília, DF, 12 nov. 2002. p. 32-54.

BRASIL. Ministério da Saúde. Portaria n 1.6oo, de 7 de julho de 2011. Reformula a Política Nacional de Atenção às Urgências e institui a Rede de Atenção às Urgências no Sistema Único de Saúde (SUS). Diário Oficial da União, Brasília, DF, 8 jul. 2011. p. 69-70.

CORDEIRO JÚNIOR, W. A gestão de risco na urgência. Belo Horizonte: Grupo Brasileiro de Classificação de Risco, 2008.

DAIN, S. Os vários mundos do financiamento da saúde no Brasil: uma tentativa de integração. Ciência \& Saúde Coletiva, Rio de Janeiro, v. 12, p. 1851-1864, 2007. Suplemento. 
FONTANELLA, B. et al. Amostragem por saturação em pesquisas qualitativas em saúde: contribuições teóricas. Cadernos de Saúde Pública, Rio de Janeiro, v. 24, n. 1, p. 17-27, 2008.

GARLET, E. R. et al. Organização do trabalho de uma equipe de saúde no atendimento ao usuário em situações de urgência e emergência. Texto \& Contexto - Enfermagem, v. 18, n. 2, p. 266-272, 2009. Disponível em: <http://www. scielo.br/scielo.php?script=sci_arttext\&pid =So104-07072009000200009>. Acesso em: 24 out. 2010.

GOULART, F. Descentralização e regionalização do SUS na década de 1990. In: TASCA, R. (Coord.). Redes e regionalização em saúde no Brasil e na Itália: lições aprendidas e contribuições para o debate. Brasília, DF: Organização Pan-Americana da Saúde, 2011. p. 29-42.

HENDERSON, A. C. Patient assessment in emergency medical services: complexity and uncertainty in street-level patient processing. Journal of Health and Human Services Administration, Montgomery, v. 35, n. 4, p. 505538, 2013.

INOJOSA, R. M. Redes de compromisso social. Revista de Administração Pública, Rio de Janeiro, v. 33, n. 5, p. 115-141, 1999. Disponível em: <http:// www.ea.ufrgs.br/pos_graduacao/especializacao/ turmas/esp2005/social2005/Download/ ArquivoProfessor/INOJOSA.PDF $>$. Acesso em: 17 ago. 2010.

IBGE - INSTITUTO BRASILEIRO DE GEOGRAFIA E ESTATÍSTICA. Censo demográfico 2010. Rio de janeiro: 2012. Disponível em: <http:// www.ibge. com.br/cidadesat $>$. Acesso em: 11 jan. 2012.

IOM - INSTITUTE OF MEDICINE. Regionalizing emergency care: workshop summary. Washington, DC: The National Academies Press, 2010.

LOPES, M. O Sistema de Atendimento das Emergências Médicas. In:_____. Emergências médicas. 5. ed. Rio de Janeiro: Guanabara, 1989. p. $2-6$.
MACHADO, C. V.; SALVADOR, F. G.; O'DWYER, G. Serviço de Atendimento Móvel de Urgência: análise da política brasileira. Revista de Saúde Pública, v. 45, n. 3, p. 519-528, 2011.

MALACHIAS, I.; LELES, F. A. G.; PINTO, M. A. S. Plano Diretor de Regionalização da Saúde de Minas Gerais. Belo Horizonte: Secretaria de Estado de Saúde de Minas Gerais, 2010.

MARQUES, A. J. S. Rede de Atenção a Urgência e Emergência na Macrorregião Norte de Minas Gerais. Belo Horizonte: Secretaria de Estado de Saúde de Minas Gerais, 2009.

MARQUES, A. J. S. et al. Rede de Urgência e Emergência. In: MARQUES, A. J. S.; MENDES, H. O. L. (Org.). Choque de gestão em Minas Gerais: resultado na saúde. Belo Horizonte: Secretaria de Estado de Saúde de Minas Gerais, 2010. p. 117-135.

MENDES, A.; MARQUES, R. M. O financiamento do SUS sob os "ventos" da financeirização. Ciência \& Saúde Coletiva, Rio de Janeiro, v. 14, n. 3, p. 841850, 2009.

MENDES, E. V. As Redes de Atenção à Saúde: revisão bibliográfica, fundamentos, conceito e elementos constitutivos. In: MENDES, E. V. As redes de atenção à saúde. Brasília, DF: Organização Pan-Americana da Saúde, 2011. p. 61-208.

MENDES, E. V.; SILVA, V. H. Caso 2: o Complexo Regulador Municipal de Saúde de Guarulhos. In: MENDES, E. V. (Coord.). Inovação nos sistemas logísticos: resultados do laboratório de inovação sobre redes integradas de atenção à saúde baseadas na APS. Brasília, DF: Organização PanAmericana da Saúde, 2010. p. 83.

MINAS GERAIS. Secretaria de Estado da Saúde. Resolução $n^{\circ}$ 1.771, de 13 de fevereiro de 2009. Aprova as normas gerais para implantação do incentivo aos hospitais da Rede de Resposta Hospitalar às Urgências da Macrorregião Norte no Estado de Minas Gerais. Belo Horizonte, 2009.

MINAS GERAIS. Secretaria de Estado da Saúde. Resolução n. 2.607, da SES/MG, de 07 de dezembro de 2010. Aprova as normas gerais para implantação das Redes Regionais de Urgência e Emergência no Estado de Minas Gerais. Belo Horizonte, 2010. 
MINAS GERAIS. Secretaria de Estado da Saúde. Deliberação CIB-SUS/MG No 978, de 16 de novembro de 2011. Aprova o ajuste do Plano Diretor de Regionalização - PDR/MG e diretrizes para o ajuste em 2013. Belo Horizonte, 2011a.

MINAS GERAIS. Secretaria de Estado da Saúde. Rede de Urgência e Emergência: Minas Gerais. Belo Horizonte, 2011b.

MINAS GERAIS. Secretaria de Estado da Saúde. Resolução SES No 2.838 , de 14 de junho de 2011. Define critérios para implantação e implementação do Protocolo de Classificação de Risco no Serviço de Urgência e Emergência - Sistema Manchester, como linguagem única adotada em urgência e emergência no Estado de Minas Gerais. Belo Horizonte, 2011c.

O'DWYER, G. et. al. Avaliação dos serviços hospitalares de emergência do estado do Rio de Janeiro. Ciência \& Saúde Coletiva, Rio de Janeiro, v. 13 , n. 5, p. 1637-1648, 2008.
O’DWYER, G. A gestão da atenção às urgências e o protagonismo federal. Ciência \& Saúde Coletiva, Rio de Janeiro, v. 15, n. 5, p. 2395-2404, 2010.

SANTA CATARINA. Secretaria de Estado da Saúde. Plano Estadual de Saúde. Florianópolis, 2003.

SANTOS J. S. et al. Avaliação do modelo de organização da Unidade de Emergência do HCFMRP-USP, adotando, como referência, as políticas nacionais de atenção às urgências e de humanização. Medicina, Ribeirão Preto, v. 36, n. 2/4, p. 498-515, 2003.

SCARPELINI, S. A Organização do Atendimento às Urgências e Trauma. Medicina, Ribeirão Preto, v. 40, n. 3, p. 315-320, 2007.

SILVA, M. V. et al. Bases conceituais e programáticas do choque de gestão na saúde em Minas Gerais. In: MARQUES, A. J. S. et al. (Org.). $O$ choque de gestão na saúde em Minas Gerais. Belo Horizonte: Secretaria de Estado de Saúde de Minas Gerais, 2009. p. 29-44

\section{Agradecimentos}

Agradecemos aos membros do Comitê Gestor da RAUE/MNMG e aos profissionais que contribuíram para a realização deste trabalho, em especial à Coordenação Estadual da Urgência e Emergência e a Superintendência Regional de Saúde de Montes Claros. Ao Prof. Eugênio Vilaça Mendes, que foi o grande inspirador na seleção do objeto de estudo, pela generosidade nas informações, no fornecimento de documentos preciosos e pela sua disponibilidade nas discussões.

\section{Contribuição dos autores}

Torres foi responsável pela concepção e delineamento do estudo, análise e interpretação dos dados, redação do artigo e aprovação da versão final. Belisário participou da concepção e delineamento do estudo, análise e interpretação dos dados e revisão crítica e aprovação da versão final. Melo fez a revisão crítica e aprovação da versão final.

Recebido: 06/07/2013

Reapresentado: 31/01/2014

Aprovado: 18/02/2014 